\title{
Prevalence of sealants in relation to dental caries on the permanent molars of 12 and 15-year-old Greek adolescents. A national pathfinder survey
}

\author{
Constantine J Oulis ${ }^{1 *}$, Elias D Berdouses², Eleni Mamai-Homata ${ }^{3}$, Argyro Polychronopoulou ${ }^{3}$
}

\begin{abstract}
Background: The use of sealants as an effective measure for the prevention of pit and fissure caries in children has been well documented by several studies; either they are used on an individual or on a public health basis. In order to plan and establish a national preventive program with sealants in a community, it is mandatory to know the epidemiological pattern of caries along with other variables influencing their use and effectiveness. Aims: To assess the utilization and distribution pattern of pit and fissure sealants on the first and second permanent molars of Greek adolescents and to evaluate whether the existing usage of sealants and some socio-demographic factors are correlated to caries prevalence on the population examined
\end{abstract}

Methods: A stratified cluster sample of 2481 Greek adolescents was selected according to WHO guidelines (1224 twelve and 1,257 fifteen-year-old), living in urban and rural areas in 11 districts within the country. Five calibrated examiners carried out clinical examinations, recording caries experience at the dentine threshold (BASCD criteria) and presence or absence of sealants along with Socio-demographic indicators associated with oral health. Mann Whitney and Pearson's chi-square non parametric tests were utilized for assessing the data. The level of significance was $p<0.05$.

Results: Sealants utilization varied considerably within the different districts, with 8,3\% of the 12 and 8,0\% of the 15 -year-old adolescents having at least one sealed molar. Sealants reduced DMFS scores by $11 \%$ in the 12 -yearolds and by $24 \%$ in the 15 -year-olds, while 15 -year-old adolescents from rural areas had a statistically significant ( $p=0.002$ ) less chance of having sealants $(71 \%)$ compared to children from urban areas. Girls had higher chance to receive sealants in both age groups (26\% for the 12 and 19\% for the 15-year-old) as well as patients that visited the dentist for prevention compared to those visiting the dentist because they thought they needed a restoration or because they were in pain.

Conclusions: The finding that sealants reduced DMFS scores despite their very low utilization, along with the high prevalence of dental caries found on the occlusal surfaces of the posterior teeth of Greek adolescents, is calling for a national preventive program with sealants which could eliminate caries to a larger extent.

\section{Background}

Although the overall caries rates have decreased considerably in most industrialized countries, the percentage of caries in pit and fissures compared to smooth surfaces has increased [1] making pits and fissures to constitute in some countries the most vulnerable sites raising the total DMFT. According to National center

\footnotetext{
* Correspondence: cjoulis@paedoclinic.gr

'Associate Professor, Department of Paediatric Dentistry Dental School, University of Athens, Athens, Greece

Full list of author information is available at the end of the article
}

for health statistics in USA [2] the prevalence of dental caries increases with age, from $21 \%$ (6-11 year old) to $67 \%$ in adolescents (16-19 year old) with $90 \%$ of carious lesions found in occlusal surfaces of molars in children and young adults. In line with the above are the findings of a study by Whelton et al. [3], in which $81 \%$ of the DMFS of 4.0 and $72 \%$ of the DMFS of 6.1, in fluoridated and non-fluoridated areas respectively, occurs in pit and fissure surfaces of 15-year-old adolescents. Dental sealants are applied as a preventive measure to cover pit and fissures on the occlusal surfaces of children or teeth

\section{() Biomed Central}


at risk for developing caries. The effectiveness of fissure sealants (FS) in preventing caries on pit and fissures of children has been well documented [4,5] and their effectiveness is dependent on the caries risk of the individuals [6] and the caries prevalence of the country [7]. In particular, studies have shown that the caries-free status of children 6-17 years of age has been associated with subsequent sealant placement [8].

Based on these findings and in an attempt to reduce caries on pit and fissures, several countries introduced the use of FS in school-based or public preventive programs with excellent results. According to Wendt et al. [9] and Parnell et al. [10], a structured fissure sealing programme is of great benefit to oral health of children since those who had no sealants had significantly poorer dental health than children who had all four first permanent molars sealed. In addition, it has been also suggested [11], that the overall less caries found in the Irish population might have been contributed to the existence of a pit and fissure sealant program delivered by the dental public health service in Ireland.

Some researchers believe that, FS can be effective in countries with DMFT below 2 and especially if the target is to lower the DMFT from 1.5 to 1.0 [12]. However, some other studies have shown that the higher the DMFT scores, the higher the caries reduction and caries free children when FS are used [13,14].

Based on the findings of the last National Oral Health survey in Greece[6] that most of the caries experience of the 12-year-old with a DMFS $=3.58$ and of the 15 year-old with a DMFS $=5.36$, was found on the occlusal surfaces of molar teeth a more tooth surface targeting preventive program with sealants could eliminate caries to a large extent. However, for such a sealant preventive program, some knowledge regarding the existing usage of sealants in relation to caries and the confounding factors influencing their use need to be answered, in order to determine the feasibility and appropriateness of this type of intervention at a National level.

Therefore the aim of this study was to assess the utilization and distribution pattern of pit and fissure sealants on the first and second permanent molars of Greek adolescents and to evaluate whether the existing usage of sealants and some socio-demographic factors are correlated to caries prevalence on the population examined.

\section{Methods}

As part of a National pathfinder survey a stratified cluster sample of 2481 (1224 twelve and 1257 fifteen-yearold) adolescents of Greek nationality leaving in urban and rural areas, was selected according to the WHO guidelines [15].

The study covered two large cities, six counties, two islands in the Aegean Sea and one island in the Ionian
Sea. Three communities with different socio-economic backgrounds were selected randomly within each of the large cities, while one urban and one rural community were selected randomly within each county or island. Therefore, the survey was conducted in 14 urban and 8 rural cites. Stratified random sampling was employed to select two schools from each city.

Five well-calibrated examiners assisted by one assistant as a recorder carried out the clinical examinations, which took place in the classrooms of the selected schools under standardized conditions recommended by the WHO. The examinations were carried out under artificial light using dental mirrors and the WHO CPITN periodontal probe. Cotton rolls and gauze were available for moisture control and removal of plaque when necessary. The recorded variables were caries experience, sealant's presence (regardless if it was total or partial), periodontal status, and oral hygiene level. Dental caries was recorded at the dentine threshold according to the agreed BASCD criteria and standards [16] set out in the BASCD trainers' pack [17]. Sociodemographic indicators associated with oral health such as: location (urban-rural), gender, parent's education level, type and mode of preventive measures and reason for visiting a dentist were collected via a questionnaire filled by the adolescent. A level of at least $85 \%$ for interand intra-examiner agreement was obtained for the recording of dental caries and sealant's presence in order for the calibration to end as successful.

\section{Statistical analysis}

DMFS variable did not present Gaussian distribution and it received positive values only, the values were skewed positively and presented over dispersion. Therefore, the effect of this variable was analysed with generalized linear models that compensate for over dispersion namely the negative binomial regression analysis. The estimated coefficient was the incidence rate ratio (IRR). In order to evaluate the possibility of the presence of sealant even in one tooth logistic regression models were used. The estimated coefficient was odds ratio (OR) along with the 95\% confidence interval and the $p$ values. The comparisons were estimated against one of the categories that was considered baseline. Also, frequencies, proportions, $\chi^{2}$ test and the non parametric tests Mann-Whitney and Kruskal-Wallis were used to describe and evaluate the distribution of sealants in the sample. The level of significance was set at $\mathrm{p}<0.05$. Patients that had never visited a dentist were excluded from calculation of the probability to receive sealants. The clinical examination and the registration of the dental condition of the individuals were possible after parental consent, permission from the Ministry of Education and the ethical approval of the committee of 
Research and Deontology in Dentistry of the University of Athens.

\section{Results}

Table 1 presents the distribution of the sample according to district, DMFT and DMFS values, gender, location and reason for visiting a dentist as well as the contribution of molars to the DMFT. A very small percentage, less than $2 \%$, of the sample in both age groups did not have any dental visit. The variation of the DMFT value was from 1.50 in the district of Attica to 2.87 in the district of Ioannina for the 12-year-old group and 2.35 in the district of Attica to 4.32 in the district of Achaia. The DMFT and DMFS values for the 12-yearold group were 2.05 and 3.58 respectively and for the 15 -year-old were 3.19 and 5.36. The most common reason to visit the dentist was prevention followed by restoration while pain was the least common cause to visit but still accounting for $18.6 \%$ and $16.5 \%$ for the 12 and 15 -year-old group respectively. About $20 \%$ of the sample came from rural areas and $80 \%$ from urban for both age groups. Caries free children accounted for $37.1 \%$ and $28.9 \%$ for the two age groups, respectively.
First and second molar DMFT value was 1.62 for the 12 and 2.48 for the 15 -year-old adolescents.

In table 2, the distribution of sealant and caries prevalence by age, tooth type and surface of first and second permanent molars of Greek adolescents is presented. Four percent of the maxillary and five percent of the mandibular $1^{\text {st }}$ permanent molars of the 12-year-old group had sealants while $4 \%$ of the $1^{\text {st }}$ permanent molars in both arches, of the 15-year-old group were sealed. Eight percent of the total sample in both age groups, presented with at least one posterior tooth sealed. First molars were sealed more often than second molars in both age groups. Sealants were found in 8.3\% and $1.4 \%$ of the first and second molars in 12 and $7.4 \%$ and $2.2 \%$ in 15 -year-old respectively.

Sealants utilization varied considerably between the different districts (table 3), with the two most populated districts of the country, Attica and Thessaloniki showing higher prevalence of sealants use compared to other districts. Multifactorial logistic regression analysis was used to evaluate the effect of different factors on the probability of a child to receive sealant. Children in all districts presented a lower probability $(<1)$ of receiving

Table 1 Distribution of 12 and 15-year-old adolescents, according to district, DMFT and DMFS values, gender, location and reason for visiting a dentist

\begin{tabular}{|c|c|c|c|c|c|c|}
\hline \multirow[b]{2}{*}{ District } & \multicolumn{3}{|c|}{ 12-year-old } & \multicolumn{3}{|c|}{15 -year-old } \\
\hline & $\mathrm{N}$ & DMFT (SD) & DMFS (SD) & $\mathrm{N}$ & DMFT (SD) & DMFS (SD) \\
\hline Attica* & 160 & $1.50(2.43)$ & $2.69(5.69)$ & 150 & $2.35(3.09)$ & $3.69(5.76)$ \\
\hline Achaia & 100 & 2.67 (3.19) & $4.62(7.01)$ & 100 & $4.32(4.13)$ & $7.12(8.50)$ \\
\hline Evros & 100 & $2.24(2.64)$ & $3.61(4.80)$ & 114 & 3.35 (3.37) & $5.25(6.08)$ \\
\hline Thessaloniki & 154 & $1.28(1.78)$ & $2.33(4.30)$ & 155 & $2.66(3.20)$ & $4.45(6.08)$ \\
\hline loannina & 101 & $2.87(2.97)$ & $5.08(8.76)$ & 105 & $3.76(3.05)$ & $6.11(6.10)$ \\
\hline Kastoria & 101 & $2.34(2.25)$ & $4.40(5.15)$ & 104 & $3.26(3.72)$ & $6.34(8.72)$ \\
\hline Keffalonia & 101 & $1.58(2.16)$ & $2.60(4.76)$ & 101 & $2.68(2.92)$ & $4.31(5.40)$ \\
\hline Larisa & 101 & $2.38(2.70)$ & $3.67(4.82)$ & 105 & $3.54(3.75)$ & 5.53 (6.74) \\
\hline Lesvos & 100 & $2.20(2.04)$ & $3.73(4.34)$ & 108 & $3.08(2.77)$ & 4.87 (4.79) \\
\hline Naxos & 102 & $2.26(2.75)$ & $3.89(6.30)$ & 104 & $3.75(4.16)$ & 6.35 (7.96) \\
\hline Chania & 104 & $1.97(2.05)$ & $3.97(5.07)$ & 111 & $2.93(3.43)$ & $6.13(9.20)$ \\
\hline Total & 1224 & $2.05(2.50)$ & $3.58(5.64)$ & 1257 & 3.19 (3.45) & $5.36(6.96)$ \\
\hline Gender & & $\mathrm{N}(\%)$ & & & $\mathrm{N}(\%)$ & \\
\hline Male & & $580(47.4)$ & & & $549(43.7)$ & \\
\hline Female & & 644 (52.6) & & & 708 (56.3) & \\
\hline No Dental Visit & & $19(1.6)$ & & & $18(1.4)$ & \\
\hline \multicolumn{7}{|c|}{ Reason for Dental Visit } \\
\hline Pain & & $224(18.6)$ & & & $205(16.5)$ & \\
\hline Restoration & & $424(35.2)$ & & & $475(38.3)$ & \\
\hline Prevention & & $557(46.2)$ & & & $559(45.1)$ & \\
\hline Rural & & $248(20.3)$ & & & $252(20.0)$ & \\
\hline Urban & & $976(79.7)$ & & & $1005(80.0$ & \\
\hline Children with caries & & $770(62.9)$ & & & $894(71.1)$ & \\
\hline DMFT of molars & & 1.62 & & & 2.48 & \\
\hline
\end{tabular}


Table 2 Distribution of sealant prevalence of the first and second permanent molars of Greek 12 and 15 -year-old adolescents

\begin{tabular}{|c|c|c|c|c|c|c|c|c|}
\hline & \multicolumn{8}{|c|}{ 12-year-old } \\
\hline & 16 & 26 & 36 & 46 & 17 & 27 & 37 & 47 \\
\hline & N (\%) & N (\%) & $\mathrm{N}(\%)$ & $\mathrm{N}(\%)$ & N (\%) & $\mathrm{N}(\%)$ & $\mathrm{N}(\%)$ & N (\%) \\
\hline Occlusal & $51(4.2)$ & $54(4.4)$ & $65(5.3)$ & $61(5.0)$ & $4(0.5)$ & $3(0.3)$ & $10(1.0)$ & $8(0.8)$ \\
\hline Lingual & $47(3.8)$ & $54(4.4)$ & & & $4(0.5)$ & $3(0.3)$ & & \\
\hline Buccal & & & $61(5.0)$ & $58(4.7)$ & & & $10(1.0)$ & $8(0.8)$ \\
\hline Teeth with caries & $401(32.8)$ & 390 (31.9) & $468(38.2)$ & $476(38.9)$ & $33(4.0)$ & $26(3.0)$ & $94(9.4)$ & $90(7.4)$ \\
\hline Teeth without caries & $823(67.2)$ & $834(68.1)$ & $756(61.8)$ & $748(61.1)$ & $791(96.0)$ & $835(97.0)$ & 904 (90.6) & $912(74.5)$ \\
\hline Teeth with Sealants & $52(4.2)$ & $54(4.4)$ & $65(5.3)$ & $61(5.0)$ & $4(0.5)$ & $3(0.3)$ & $10(1.0)$ & $8(0.7)$ \\
\hline \multicolumn{9}{|c|}{ Patients with at least one sealant: $102(8.3)$} \\
\hline & \multicolumn{8}{|c|}{15 -year-old } \\
\hline Occlusal & $55(4.4)$ & $52(4.1)$ & $50(4.0)$ & $55(4.4)$ & $13(1.0)$ & $10(0.8)$ & $14(1.1)$ & $15(1.2)$ \\
\hline Lingual & $52(4.1)$ & $49(3.9)$ & & & $13(1.0)$ & $11(0.9)$ & & \\
\hline Buccal & & & $48(3.8)$ & $54(4.3)$ & & & $13(1.0)$ & $15(1.2)$ \\
\hline Teeth with caries & $512(40.7)$ & $488(38.8)$ & $586(46.6)$ & $607(48.3)$ & $158(12.6)$ & $194(15.4)$ & $300(23.9)$ & $274(21.8)$ \\
\hline Teeth without caries & $745(59.3)$ & $769(61.2)$ & $671(53.4)$ & $650(51.7)$ & $1099(87.4)$ & $1063(84.6)$ & $957(76.1)$ & $983(78.2)$ \\
\hline Teeth with sealants & $55(4.4)$ & $52(4.1)$ & $50(4.0)$ & $55(4.4)$ & $13(1.0)$ & $11(0.9)$ & $14(1.1)$ & $15(1.2)$ \\
\hline
\end{tabular}

sealants compared to Attica, except of the district of Larisa in the 12-year-old group (1.17) and district of Lesvos (1.45) in the 15-year-old group. Fifteen year-old adolescents from rural areas had a statistically significant $(p=0.002)$ less chance $(71 \%)$ of having sealants compared to adolescents from urban areas. Girls had higher chance to receive sealants in both age groups (26\% for the 12 and $12 \%$ for the 15 -year-old), but not with statistically significant difference.

In the 15-year-old group, patients that visited the dentist because they thought they needed a restoration or they were in pain had a reduced chance of receiving a sealant by $24 \%$ and $43 \%$ respectively, compared to patients that visited the dentist for prevention but not in a statistically significant level. In the 12-year-old group, patients that visited the dentist because they thought they needed a restoration had a not statistically significant increased chance (37\%) of receiving a sealant compared to patients that visited for prevention. On the contrary, patients that visited because of pain had a statistically significant reduced chance (57\%) of receiving sealant ( $\mathrm{p}=0.029$ ) compared to patients that visited the dentist for prevention. Also, as the educational level of parents increases the probability of their children to receive sealant increases statistically significant.

Table 4 presents the distribution of caries in the different surfaces of the teeth. It was found that $16.8 \%$ were in the anterior teeth and $83.2 \%$ in the posterior teeth of the 12-year-old group while the respective values for the 15 -year-old group were $13.2 \%$ for the anterior and $86.9 \%$ for the posterior teeth. Caries located in pit and fissures (occlusal surface, lingual of maxillary and buccal of mandibular molars) accounted for 56.2\% of the total caries on 12-year-old and $58.0 \%$ of the 15 year-old children or for $67.6 \%$ and $66.7 \%$ of the caries of the posterior surfaces in the two age groups respectively.

The effect of sealant on DMFS was evaluated with negative binomial regression analysis and it was found that sealants reduced caries prevalence by $11 \%$ in the 12-year-old group (not statistically significant) and by a statistically significant level of $24 \%$ in the 15 -year-old group (table 5).

\section{Discussion}

This study, as part of the first oral health National pathfinder survey of the Hellenic population, was aimed to assess the utilization and the distribution pattern of sealant use in 12 and 15-year-old adolescents in relation to their caries prevalence and the influence of several sociodemographic parameters.

Based on the findings of this study, sealant utilization in adolescents throughout the country was very low (8\%) and most likely this might be attributed to lack of awareness of the public and that the dentists have not been convinced on the usefulness and effectiveness of sealants on caries prevention. This hypothesis is supported from the findings of another study conducted in Greece aiming to investigate the dentist's beliefs on sealant use [18]. According to this study, although $68.8 \%$ of the general dental practitioners in Greece believe in prevention and $59.0 \%$ believe in the effectiveness of sealants only $30.3 \%$ apply them in practice due to a number of 
Table 3 Variables predicting sealant placement on permanent molars of 12 and 15-year-old Greek adolescents (Multifactorial - Logistic Regression Analysis)

\begin{tabular}{|c|c|c|c|c|c|c|}
\hline \multirow[b]{2}{*}{ District } & \multicolumn{3}{|c|}{ 12-year-old } & \multicolumn{3}{|c|}{ 15-year-old } \\
\hline & $\begin{array}{l}\text { Odds } \\
\text { Ratio }\end{array}$ & $\begin{array}{c}95 \% \\
\text { C.I. }\end{array}$ & $\begin{array}{c}\text { P- } \\
\text { value }\end{array}$ & $\begin{array}{l}\text { Odds } \\
\text { Ratio }\end{array}$ & $\begin{array}{l}95 \% \\
\text { C.I. }\end{array}$ & $\begin{array}{l}\text { P- } \\
\text { value }\end{array}$ \\
\hline Attica* & 1 & & & 1 & & \\
\hline Achaia & 0.37 & $\begin{array}{l}(0.12 \\
1.14)\end{array}$ & 0.084 & 0.33 & $\begin{array}{l}(0.11 \\
1.02)\end{array}$ & 0.053 \\
\hline Evros & 0.31 & $\begin{array}{l}(0.11 \\
0.84)\end{array}$ & $0.022^{1}$ & 0.44 & $\begin{array}{l}(0.19 \\
1.02)\end{array}$ & 0.055 \\
\hline Thessaloniki & 0.63 & $\begin{array}{l}(0.33 \\
1.19)\end{array}$ & 0.155 & 0.41 & $\begin{array}{l}(0.19 \\
0.88)\end{array}$ & $0.021^{1}$ \\
\hline loannina & 0.41 & $\begin{array}{c}(0.16 \\
1.07)\end{array}$ & 0.068 & 0.44 & $\begin{array}{l}(0.19 \\
1.05)\end{array}$ & 0.066 \\
\hline Kastoria & 0.52 & $\begin{array}{l}(0.23 \\
1.18)\end{array}$ & 0.119 & 0.20 & $\begin{array}{l}(0.07 \\
0.59)\end{array}$ & $0.004^{1}$ \\
\hline Keffalonia & 0.26 & $\begin{array}{l}(0.10 \\
0.72)\end{array}$ & $0.009^{1}$ & 0.60 & $\begin{array}{l}(0.24 \\
1.53)\end{array}$ & 0.288 \\
\hline Larisa & 1.17 & $\begin{array}{l}(0.58 \\
2.35)\end{array}$ & 0.655 & 0.45 & $\begin{array}{l}(0.19 \\
1.07)\end{array}$ & 0.071 \\
\hline Lesvos & 0.38 & $\begin{array}{l}(0.14 \\
1.05)\end{array}$ & 0.063 & 1.45 & $\begin{array}{l}(0.68 \\
3.10)\end{array}$ & 0.335 \\
\hline Naxos & 0.26 & $\begin{array}{l}(0.09 \\
0.79)\end{array}$ & $0.018^{1}$ & 0.53 & $\begin{array}{l}(0.20 \\
1.38)\end{array}$ & 0.194 \\
\hline Chania & 0.16 & $\begin{array}{l}(0.04 \\
0.07)\end{array}$ & $0.015^{1}$ & 0.44 & $\begin{array}{l}(0.17 \\
1.16)\end{array}$ & 0.097 \\
\hline
\end{tabular}

Mother's Educational Levels

\begin{tabular}{|c|c|c|c|c|c|c|}
\hline College* & 1 & & & 1 & & \\
\hline High & 0.60 & $\begin{array}{l}(0.39, \\
0.94)\end{array}$ & $0.026^{1}$ & 0.61 & $\begin{array}{l}(0.41, \\
1.01)\end{array}$ & 0.055 \\
\hline Elementary & 0.23 & $\begin{array}{l}(0.09, \\
0.58)\end{array}$ & $0.002^{1}$ & 0.54 & $\begin{array}{l}(0.26, \\
0.95)\end{array}$ & 0.035 \\
\hline
\end{tabular}

Reason Visiting a Dentist

Prevention* 1

\begin{tabular}{lllllll} 
Restoration & 1.37 & $\begin{array}{c}(0.86, \\
\text { Pain }\end{array}$ & 0.184 & 0.76 & $(0.47$, & 0.264 \\
& & $2.18)$ & & & $1.23)$ & \\
& 0.43 & $(0.21$, & $\mathbf{0 . 0 2 9}$ & 0.57 & $(0.29$, & 0.092 \\
& & $0.92)$ & & & $1.10)$ & \\
\hline
\end{tabular}

Urban/

Rural

\begin{tabular}{|c|c|c|c|c|c|c|}
\hline & \multirow{2}{*}{$\begin{array}{l}0.29 \\
1\end{array}$} & \multirow[t]{2}{*}{$\begin{array}{l}(0.13- \\
0.63)\end{array}$} & \multirow[t]{2}{*}{$0.002^{1}$} \\
\hline Urban* & & & & & & \\
\hline \multicolumn{7}{|l|}{ Gender } \\
\hline Male & 1 & & & 1 & & \\
\hline Female & 1.26 & $\begin{array}{l}(0.84, \\
1.89)\end{array}$ & 0.272 & 1.12 & $\begin{array}{l}(0.74 \\
1.68)\end{array}$ & 0.603 \\
\hline
\end{tabular}

*Baseline Category.

${ }^{1}$ Variable with statistical difference compared with the baseline.

concerns they raise about their use. The expressed concerns such as "parents do not pay" or "unaware how to use them" or "other preventive measures like oral hygiene are sufficient to prevent caries" show that there is a serious lack of the appropriate knowledge between general dental practitioners in Greece, regarding sealant effectiveness [19]. Dentist's reservations of sealant
Table 4 Distribution of caries in 12 and 15-year-old adolescents according to surface of anterior and posterior teeth

\begin{tabular}{|c|c|c|c|}
\hline & \multicolumn{3}{|c|}{ 12-year-old } \\
\hline & $\begin{array}{c}\text { Anterior } \\
\mathrm{N}(\%)\end{array}$ & $\begin{array}{c}\text { Posterior } \\
\mathrm{N}(\%)\end{array}$ & Total \\
\hline Occlusal & & $1900(43.3)$ & $1900(43.3)$ \\
\hline Mesial & $249(5.7)$ & $535(12.2)$ & $784(17.9)$ \\
\hline Distal & $157(3.6)$ & $323(7.4)$ & $480(10.9)$ \\
\hline Lingal & $206(4.7)$ & $413(9.4)$ & $619(14.1)$ \\
\hline Buccal & $124(2.8)$ & $483(11.0)$ & $607(13.8)$ \\
\hline Total & $736(16.8)$ & $3654(83.2)$ & $4390(100)$ \\
\hline DMFS & 0.60 & 2.98 & 3.58 \\
\hline \multicolumn{3}{|c|}{ Pit \& Fissures out of total caries } & $2469(56.2)$ \\
\hline \multicolumn{3}{|c|}{ Pit \& Fissures out of caries in posterior teeth } & $2469(67.6)$ \\
\hline & \multicolumn{3}{|c|}{ 15-year-old } \\
\hline Occlusal & & $3131(46.4)$ & $3131(46.4)$ \\
\hline Mesial & $321(4.8)$ & $883(13.1)$ & $1204(17.8)$ \\
\hline Distal & $172(2.6)$ & $638(9.5)$ & $810(12.0)$ \\
\hline Lingal & $211(3.2)$ & $591(8.8)$ & $802(12.0)$ \\
\hline Buccal & $177(2.6)$ & $619(9.2)$ & $796(11.8)$ \\
\hline Total & $881(13.1)$ & $5862(86.9)$ & $6743(100)$ \\
\hline DMFS & 0.70 & 4.66 & 5.36 \\
\hline \multicolumn{3}{|c|}{ Pit \& Fissures out of total caries } & $3911(\mathbf{5 8 . 0 )}$ \\
\hline \multicolumn{3}{|c|}{ Pit \& Fissures out of caries in posterior teeth } & $3911(66.7)$ \\
\hline
\end{tabular}

effectiveness and unawareness on how to use them might have been the reasons for not being successful in persuading the parents to accept sealants. On the other hand, dentists are very important in educating parents on carries prevention issues and they can increase sealant use in the population. This occurs because parents are more inclined to accept advice from them on caries prevention since dentists are the most appropriate source of information on such issues [19].

The low prevalence of sealants on both ages might also explains in part the high prevalence of caries found (almost 2-fold) in Greek adolescents compared to other European countries. Especially when, most of the caries in the two age groups (83 and $87 \%$ ) was found on the posterior teeth and the majority of it (67.6 and 66.7\%)

Table 5 Effect of sealant presence on DMFS of 12 and 15year-old Greek adolescents (Negative Binomial Regression)

\begin{tabular}{lcccccc}
\hline & \multicolumn{3}{c}{ 12-year-old } & \multicolumn{3}{c}{ 15-year-old } \\
\hline Sealants & IRR & 95\% C.I. & $\begin{array}{c}\text { P- } \\
\text { value }\end{array}$ & IRR & 95\% C.I. & $\begin{array}{c}\text { P- } \\
\text { value }\end{array}$ \\
\hline No* & 1 & & & 1 & & \\
Yes & 0.89 & $(0.65$, & 0.467 & 0.76 & $(0.57$, & $\mathbf{0 . 0 4 9 ^ { 1 }}$ \\
& $(11 \%)$ & $1.22)$ & & $(24 \%)$ & $1.00)$ & \\
\hline
\end{tabular}

*Baseline Category

${ }^{1}$ Variable with statistical difference compared with the baseline. 
was located on pit and fissures that can be mostly benefited and caries might be prevented by the use of sealants.

Despite the low sealant use, sealant placement was associated with caries reduction in both age groups. This reduction was not statistically significant (11\%) in the 12-year-old group but increased to a statistically significant $24 \%$ for the 15 -year-old group. Our findings, on the association of sealant's prevalence and DMFS reduction are in agreement with other similar studies conducted in other European countries, in which the sealant implementation resulted in significant lower DMFS values [20] and the degree of caries reduction (16-60\%) was dependent on the prevalence of sealants and the caries level of the population $[20,21]$. In Germany [21], after the introduction of sealants in a range of $16-45 \%$ of the population, DMFT index decreased from 3.54 in 1997 to 1.24 in 2004.

However, there are other countries like Denmark, where although sealant's prevalence was very high, $2 / 3$ of 15-year-old Danish children had at least one sealed molar, there was no statistical significant association of caries reduction and sealant presence [22]. According to our opinion, this might be attributed to the fact that sealants were applied on children with a very low DMFS value (2.97 compared to 5.36 of ours) and although there was such a high prevalence of sealants, it could not be further reduced This explanation might also be valid for not finding any statistically significant difference in caries reduction in the 12-year-old group of our study. This group presented with a rather low DMFS value of 3.58 which in conjunction with the low prevalence of sealants probably were not adequate to produce any statistically significant difference.

According to some researchers, sealants can be effective in countries with DMFT below 2 [12], while some others have shown that the higher the DMFT scores, the higher the caries reduction and the number of caries free children $[13,23]$. It seems that between the two factors, the DMFT value has a stronger contributing effect on caries reduction than the prevalence of sealants in the population.

Our data also showed a very large inter-district variation in sealants use and a significantly increased possibility of children of larger cities and urban areas to receive sealants compared to children from smaller cities or rural areas. This finding can be attributed to a different attitude of the population on sealant efficacy, a better access to professionally provided preventive oral health services $[22,24]$ and/or that rural areas generally have fewer dentists per population and more poverty resulting in lower access and utilization of dental care [25]. It is also known that there are striking disparities in dental disease prevalence among people based on socio-demographic characteristics, such as income, location, and parental educational level [24]. Moreover, studies have shown that the percentage of children with dental sealants is directly related to the community's SES [26] and that children from low income and minority families have fewer dental visits, and fewer protective sealants [27].

The solution to the problem for a population with such a low sealant prevalence, high DMFS values and large inter-district variation in sealant use seems to be a school-based or a national sealant programme, aiming to increase sealant's prevalence up to $40-50 \%$. Considering the findings from other similar programs in other countries, in which a caries reduction of up to $60 \%$ was succeeded after 5 years of sealant application [28], a target of reducing our adolescent's DMFS value by $50 \%$ after 5 years, seems to be very logical.

Therefore, a school-based or national sealant preventive programme is needed to be organized and implemented in Greece, with special emphasis on increasing the knowledge and awareness of dentists and the public on sealant usefulness in order to benefit all children but mainly the most disadvantageous group of children that need it the most.

\section{Conclusion}

- The survey indicated that there was a low utilization of sealants in Greece compared to other European countries and their distribution varied considerably between the different districts, showing a significant higher use in urban than in rural areas, in females than in males and in children from parents with higher educational level.

- Sealants, even in low prevalence, contributed to a significant reduction of caries in a high DMFT population suggesting that they are more effective in high DMFT populations. Also, DMFT of the population is more important for the sealant efficiency than sealant prevalence.

- Patients that visited dentists because of pain or lived in rural areas had reduced chances to receive sealants

- The high prevalence of caries found in the posterior teeth, along with the low sealant use in Greek adolescents, necessitate the establishment of a more targeted preventive program with better and more effective oral health education, which will increase the sealant use and thus can greatly reduce caries on their permanent posterior teeth.

\section{Acknowledgements}

The authors are deeply indebted to all the people from the different regions of Greece, who either as members of the board or coordinators of the local dental societies or as examiners, contributed to the completion of this 
coordinated epidemiological survey, as part of the National Program "Assessment and Promotion of the Oral Health of the Hellenic Population", which was carried out under the auspices of the Hellenic Dental Association and the coordination of Assoc. Prof. Constantine Oulis, in collaboration with the Dental Schools of Athens and Thessaloniki.

This Program was sponsored by a Colgate-Palmolive grant.

\section{Author details}

${ }^{1}$ Associate Professor, Department of Paediatric Dentistry Dental School, University of Athens, Athens, Greece. ${ }^{2}$ Paediatric Dentist, Clinical Instructor, Department of Paediatric Dentistry, Dental School, University of Athens, Athens, Greece. ${ }^{3}$ Associate Professors, Department of Preventive and Community Dentistry, Dental School, University of Athens, Athens, Greece.

\section{Authors' contributions}

CJO: conceived the study, co-organised the epidemiological survey, made the analysis and interpretation of data, discussed the quality of the paper, approved and corrected the final draft. EDB: drafted the manuscript, organised the data selection. EMH: participated in drafting the paper and discussing the relevant literature in caries epidemiology. AP: contributed in the design and sampling of the study and checked the statistical analysis.

\section{Competing interests}

The authors declare that they have no competing interests.

Received: 9 September 2010 Accepted: 14 February 2011 Published: 14 February 2011

\section{References}

1. Feigal RJ, Donly KJ: The use of pit and fissure sealants. Pediatr Dent 2006 28(2):143-150

2. National Center for Health Statistics (NCHS): Centers for Disease Control and Prevention. National Health and Nutrition Examination Surveys 1999-2004. 2007.

3. Whelton H, O'Mullane D, Cronin M: Survey of Oral Health of Children and Adolescents 1997 - A report for the Mid-Western Health Board. Mid Western Health Board (1998). Limerick, Ireland: Mid Western Health Board, Catherine Street.

4. Beauchamp J, Caufield PW, Crall JJ, Donly K, Feigal R, Gooch B, Ismail A, Kohn W, Siegal M, Simonsen R: Evidence-based clinical recommendations for the use of pit-and-fissure sealants: a report of the American Dental Association Council on Scientific Affairs. J Am Dent Assoc 2008, 139(3):257-268.

5. Welbury R, Raadal M, Lygidakis NA: EAPD guidelines for the use of pit and fissure sealants. Eur J Paediatr Dent 2004, 5(3):179-184.

6. Oulis C, Theodorou M, Mastrogiannakis T, Mamai-Chomata E, Polychronopoulou A, Athanasouli T: Oral health status and treatment needs of the Hellenic population-proposals for improvement. Hellenic Stomatological Review 2009, 53(2):97-120.

7. Leskinen K, Ekman A, Oulis C, Forsberg H, Vadiakas G, Larmas M: Comparison of the effectiveness of fissure sealants in Finland, Sweden, and Greece. Acta Odontol Scand 2008, 66(2):65-72.

8. Ahovuo-Saloranta, Hiiri A, Nordblad A, Makela M, Worthington HV: Pit and fissure sealants for preventing dental decay in the permanent teeth of children and adolescents. Cochrane Database Syst Rev 2010, 8(4) CD001830.

9. Wendt LK, Koch G, Birkhed D: Long-term evaluation of a fissure sealing programme in Public Dental Service clinics in Sweden. Swed Dent J 2001, 25(2):61-65.

10. Parnell CA, O'Farrell M, Howell F, Hegarty M: Evaluation of a community fissure sealant programme in County Meath, Ireland. Community Dent Health 2003, 20(3):146-152.

11. Whelton $\mathrm{H}$ : Overview of the impact of changing global patterns of dental caries experience on caries clinical trials. JDR 2004, 83:29-34.

12. Marthaler TM: Changes in dental caries 1953-2003. Caries Res 2004, 38(3):173-181.

13. Vrbic V: Reasons for the caries decline in Slovenia. Community Dent Oral Epidemiol 2000, 28(2):126-132.

14. Klemme B, Tramini P, Niekusch U, Rossbach R, Schulte AG: Relationship between caries prevalence and fissure sealants among 12-year-old
German children at three educational strata. Soz Praventivmed 2004, 49(5):344-351.

15. World Health Organization: Oral Health Surveys. Basic Methods. Geneva, 3 1987.

16. Pitts NB, Evans DJ, Pine CM: British Association for the Study of Community Dentistry (BASCD) diagnostic criteria for caries prevalence surveys 1996/97. Community Dent Health 1997, 14(Suppl 1):6-9.

17. Mitropoulos C, Pitts NB, Deery C: British Association for the Study of Community Dentistry criteria for the standardised assessment of dental health (1992/93). In BASCD trainer's pack for caries prevalence studies 1992/ 93 University of Dundee; 1992.

18. Michalaki M, Sifakaki M, Oulis CJ, Lygidakis NA: Attitudes, knowledge and Utilization of fissure sealants among Greek Dentists: a national survey. European Arch Paed Dent 2010, 11(6):287-93.

19. Mafeni JO, Messer LB: Parental knowledge and attitudes towards pit and fissure sealants. Aust Dent J 1994, 39(3):172-180.

20. Caries for 12-Year-Olds by Country/Area. [http://www.whocollab.od.mah. se/countriesalphab.html].

21. Pieper K, Schulte AG: The decline in dental caries among 12-year-old children in Germany between 1994 and 2000. Community Dent Health 2004, 21(3):199-206.

22. Ekstrand KR, Martignon S, Christiansen ME: Frequency and distribution patterns of sealants among 15-year-olds in Denmark in 2003. Community Dent Health 2007, 24:26-30.

23. Klemme B, Tramini P, Niekusch U, Rossbach R, Schulte AG: Relationship between caries prevalence and fissure sealants among 12-year-old German children at three educational strata. Soz Praventivmed 2004, 49(5):344-351.

24. Kallestal C, Wall S: Socio-economic effect on caries. Incidence data among Swedish 12-14-year-olds. Community Dent Oral Epidemiol 2002, 30(2):108-114.

25. Vargas CMYJHKL: Oral health status of older rural adults in the United States. J Am Dent Assoc 2003, 134(4):479-486.

26. Gillcrist JA, Brumley DE, Blackford JU: Community socioeconomic status and children's dental health. J Am Dent Assoc 2001, 132(2):216-222.

27. Mouradian WE, Wehr E, Crall JJ: Disparities in children's oral health and access to dental care. J Am Med Assoc 2000, 284(20):2625-2631.

28. Gooch BF, Griffin SO, Gray SK, Kohn WG, Rozier RG, Siegal M, Fontana M, Brunson D, Carter N, Curtis DK, et al: Preventing dental caries through school-based sealant programs: updated recommendations and reviews of evidence. J Am Dent Assoc 2009, 140(11):1356-1365.

\section{Pre-publication history}

The pre-publication history for this paper can be accessed here: http://www.biomedcentral.com/1471-2458/11/100/prepub

\section{doi:10.1186/1471-2458-11-100}

Cite this article as: Oulis et al:: Prevalence of sealants in relation to dental caries on the permanent molars of 12 and 15-year-old Greek adolescents. A national pathfinder survey. BMC Public Health 2011 11:100.

\section{Submit your next manuscript to BioMed Central and take full advantage of:}

- Convenient online submission

- Thorough peer review

- No space constraints or color figure charges

- Immediate publication on acceptance

- Inclusion in PubMed, CAS, Scopus and Google Scholar

- Research which is freely available for redistribution 